\title{
'Iniagrape-one', a New Chilean Table Grape Cultivar
}

\author{
Carolina Uquillas ${ }^{1}$, Eduardo Torres, Antonio Ibacache, \\ and Bruno G. Defilippi
}

Agricultural Research Institute (INIA), La Platina Experimental Research Center, P.O Box 439-3, Santiago, Chile

Additional index words. cultivar, fruit breeding, Vitis vinifera, table grape

'Iniagrape-one' (Vitis vinifera L. $\times$ Vitis vinifera $\mathrm{L}$.) is a new and distinct midseasonripening, blue-black table grape cultivar for export markets that stores well for up to three months under the proper conditions. This cultivar presents large clusters and firm large berries with seed rudiments. This cultivar was released by the Table Grape Breeding Program at La Platina Experiment Research Center of the Agricultural Research Institute (INIA). It provides a black cultivar adapted to three growing regions in Chile and fulfills a niche market for black grapes. 'Iniagrapeone' fills the harvest period between the current commercial black cultivars and expands the shipping period for black grapes for the Chilean harvest season. 'Iniagrape-one' is harvested in mid-February in the central area of Chile (Aconcagua Valley), which is 1 week after 'Black Seedless' and 'Midnight Beauty' and 3 weeks before 'Autumn Royal'. It also ripens by the second week of January under warm and dry growing conditions such as those found in northern Chile (Elqui Valley).

\section{Origin}

The new Iniagrape-one cultivar resulted from controlled hybridization performed in 1998 between 'Flame Seedless' and 'Black Seedless'. Plants were produced from the maternal parent 'Flame Seedless' using embryo rescue procedures (Emershad and Ramming, 1984; Emershad et al., 1989; Ramming, 2008). The original vine was planted in 2000 at La Platina Experiment Research Center in Santiago (lat. 33 $34^{\prime} 20^{\prime \prime} \mathrm{S}$, long. $70^{\circ} 37^{\prime} 31^{\prime \prime} \mathrm{W}$, $631 \mathrm{~m}$ above sea level) selected in 2004 and tested as selection INIA-5.56.

\section{Description and Performance}

'Iniagrape-one' was evaluated in a warm and dry condition in the Elqui Valley in northern Chile (Vicuña site, lat. $30^{\circ} 2^{\prime} 18^{\prime \prime} \mathrm{S}$,

\footnotetext{
Received for publication 6 Nov. 2012. Accepted for publication $20 \mathrm{Feb} .2013$.

This research was funded by Biofrutales Consortium, CONICYT PBST PSD03 and CORFO-INNOVA 09PMG-7229.

We gratefully acknowledge Ariel Pinolef, Carmen Jopia, and Isela Escudero for their technical assistance. ${ }^{1}$ To whom reprint requests should be addressed; e-mail cuquillas@inia.cl.
}

long. $70^{\circ} 41^{\prime} 48^{\prime \prime} \mathrm{W}, 641 \mathrm{~m}$.a.s.1.) and in temperate conditions in Aconcagua Valley in central Chile (Llay-Llay site, lat. $32^{\circ} 53^{\prime} 31.5^{\prime \prime} \mathrm{S}$, long. $70^{\circ} 55^{\prime} 18.5^{\prime \prime} \mathrm{W}, 433$ m.a.s.1.) and Los Andes site (lat. $32^{\circ} 52^{\prime} 24.59^{\prime \prime} \mathrm{S}$, long. $70^{\circ} 38^{\prime} 03.11^{\prime \prime} \mathrm{W}, 790$ m.a.s.1.). At all sites, vines grafted onto 'Freedom' rootstock and planted in 2005 were cane-pruned on an overhead trellis system (pergola). Standard cultural practices were applied including annual dormant pruning, cluster tipping, gibberellic acid (GA) spray, weed control using mechanical and chemical methods, fertilization, and drip irrigation applied as needed.

The vines at Vicuña received an application of hydrogen cyanamide $(4 \%)$ in the winter (June); the vines at Los Andes and Llay-Llay were not sprayed with hydrogen cyanamide. At the three sites, the number of clusters per vine was adjusted at the berry set stage as a normal production practice and the clusters were tipped at this stage.
At Vicuña for thinning, the clusters received applications of GA at different doses depending on the evaluation season, i.e., $1 \times$ $10 \mathrm{mg} \cdot \mathrm{L}^{-1}(2009), 1 \times 15 \mathrm{mg} \cdot \mathrm{L}^{-1}(2010)$, and $2 \times 15 \mathrm{mg} \cdot \mathrm{L}^{-1}(2011)$ plus $2 \times 40 \mathrm{mg} \cdot \mathrm{L}^{-1}$ for berry sizing each year. Additionally, the distal third of the cluster was tipped and manual berry thinning was performed leaving 150 to 167 berries per cluster (Table 1). At Los Andes and Llay-Llay sites, the GA treatment was $1 \times 10 \mathrm{mg} \cdot \mathrm{L}^{-1}$ for cluster elongation (rachis, 10 to $12 \mathrm{~cm}$ length), $2 \times 10 \mathrm{mg} \cdot \mathrm{L}^{-1}$ at bloom for thinning, and $3 \times 30 \mathrm{mg} \cdot \mathrm{L}^{-1}$ to increase the berry size. The clusters were tipped and manual berry thinning was performed leaving 81 to 135 berries per cluster (Table 1).

The clusters of 'Iniagrape-one' are attractive, conical, of medium density, and large size (Fig. 1). Without application of growth regulators, cluster weight ranged from $322 \mathrm{~g}$ to $723 \mathrm{~g}$ with an overall average $525 \mathrm{~g}$. When GA was applied, overall average reaches $827 \mathrm{~g}$, ranging from $586 \mathrm{~g}$ to over $900 \mathrm{~g}$ (Table 2). The 'Iniagrape-one' yield depends on the vine crop adjustment, and the cluster weight is related to cluster tipping and berry thinning (berries per cluster). During season 2011, the production averaged $27.8 \mathrm{~kg}$ per adult vine at Vicuña, $23.1 \mathrm{~kg}$ per adult vine at Los Andes, and 29.4 at Llay-Llay (Table 1); thus, the cultivar shows a high potential yield for export.

Unlike other colored cultivars, including 'Black Seedless' (Volosky, 1985), 'Midnight Beauty' (data no shown), and 'Autumn Royal' (Dokoozlian et al., 1998), 'Iniagrape-one' has a complete uniform blue-black color without the need for any technological approach for improving this attribute such as plant growth

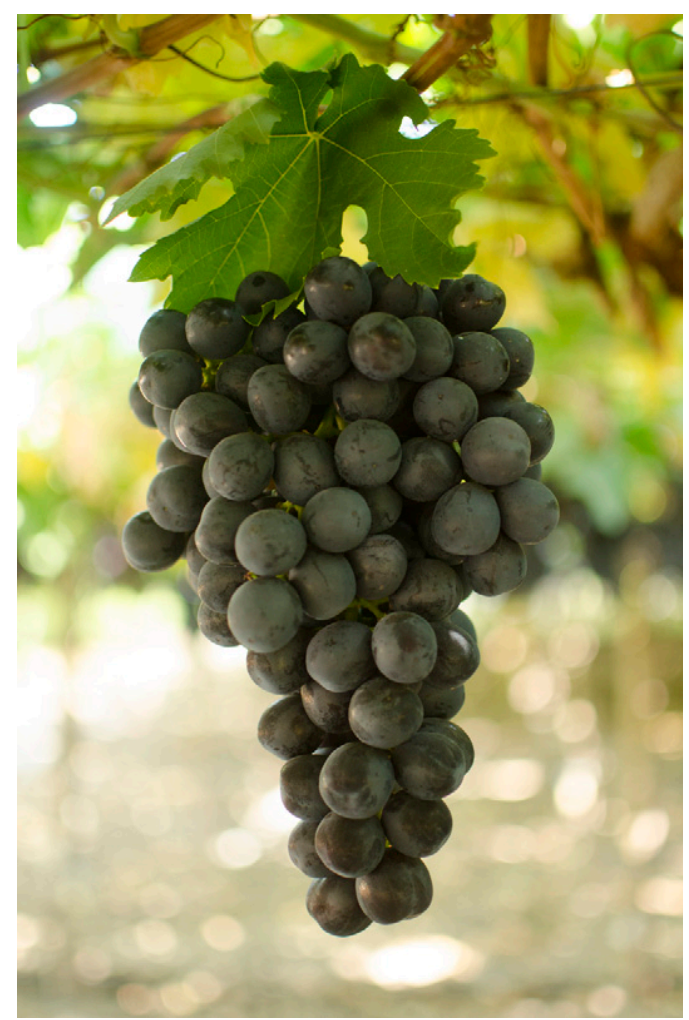

Fig. 1. Cluster of 'Iniagrape-one' grape. 
Table 1. Yield, cluster, and berry characteristics of GA-treated 'Iniagrape-one' at Vicuña, ${ }^{\mathrm{z}}$ Los Andes, ${ }^{\mathrm{y}}$ and Llay-Llay ${ }^{x}$ during three years.

\begin{tabular}{lccc}
\hline & \multicolumn{2}{c}{2009} & Llay-Llay \\
\hline Characteristic & Vicuña & Los Andes & 12 Feb. \\
\hline Harvest date & 16 Jan. & 9 Feb. & $35 \pm 0.0$ \\
Clusters per vine $^{\mathrm{w}}$ & $16 \pm 4.8$ & $28 \pm 0.0$ & $37.1 \pm 3.5$ \\
Yield $\left(\mathrm{kg} /\right.$ vine) $^{\mathrm{w}}$ & $17.8 \pm 5.3$ & $19.6 \pm 5.7$ & $1058.8 \pm 100.7$ \\
Cluster weight $(\mathrm{g})$ & $1114.3 \pm 189.9$ & $698.9 \pm 201.9$ & $134.8 \pm 4.6$ \\
Berries per cluster & $167.0 \pm 23.1$ & $99.8 \pm 20.6$ & $258.6 \pm 42.4$ \\
Berry firmness $\left(\mathrm{g} \cdot \mathrm{mm}^{-1}\right)^{\mathrm{v}}$ & - & $320.9 \pm 11.8$ & $20.8 \pm 0.3$ \\
TSS $(\%)$ & $24.2 \pm 0.8$ & $21.2 \pm 0.6$ & $0.6 \pm 0.1$ \\
TA $(\%)$ & $0.7 \pm 0.1$ & $0.7 \pm 0.1$ &
\end{tabular}

2010

\begin{tabular}{lcrr}
\hline Characteristic & Vicuña & Los Andes & Llay-Llay \\
\hline Harvest date & 13 Jan. & 23 Feb. & 18 Feb. \\
Clusters per vine $^{\mathrm{w}}$ & $15 \pm 2.2$ & $28 \pm 0.0$ & $35 \pm 0.0$ \\
Yield (kg/vine) $^{\mathrm{w}}$ & $12.8 \pm 1.8$ & $16.4 \pm 2.1$ & $20.9 \pm 0.2$ \\
Cluster weight $(\mathrm{g})^{\text {Berries per cluster }}$ & $849.7 \pm 153.4$ & $586.3 \pm 74.6$ & $597.7 \pm 6.1$ \\
Berry firmness $\left(\mathrm{g} \cdot \mathrm{mm}^{-1}\right)^{\mathrm{v}}$ & $150.0 \pm 28.8$ & $82.2 \pm 21.7$ & $81.4 \pm 8.3$ \\
TSS (\%) & - & $232.9 \pm 14.9$ & $262.3 \pm 13.7$ \\
TA $(\%)$ & $19.3 \pm 1.0$ & $20.7 \pm 0.4$ & $20.5 \pm 0.1$ \\
& $1.15 \pm 0.1$ & $0.9 \pm 0.0$ & $0.9 \pm 0.0$
\end{tabular}

\begin{tabular}{lccr}
\multicolumn{2}{c}{2011} & Llay-Llay \\
\hline Characteristic & Vicuña & Los Andes & 16 Feb. \\
\hline Harvest date & 14 Jan. & 16 Feb. & $35 \pm 0.0$ \\
Clusters per vine $^{\mathrm{w}}$ & $32 \pm 2.4$ & $28 \pm 0.0$ & $29.4 \pm 2.0$ \\
Yield $\left(\mathrm{kg} /\right.$ vine) $^{\mathrm{w}}$ & $27.8 \pm 1.9$ & $23.1 \pm 3.4$ & $841.2 \pm 58.0$ \\
Cluster weight $(\mathrm{g})$ & $869.5 \pm 234.9$ & $826.8 \pm 131.0$ & $89.2 \pm 2.2$ \\
Berries per cluster & $152.0 \pm 40.3$ & $106.3 \pm 13.1$ & $342.5 \pm 30.9$ \\
Berry firmness $\left(\mathrm{g} \cdot \mathrm{mm}^{-1}\right)^{\mathrm{v}}$ & - & $321.2 \pm 9.0$ & $19.3 \pm 0.8$ \\
TSS (\%) & $19.7 \pm 1.0$ & $18.8 \pm 0.2$ & $0.9 \pm 0.0$ \\
TA $(\%)$ & $1.13 \pm 0.1$ & $0.9 \pm 0.0$ & 0.9 \\
\hline
\end{tabular}

z,y,x Locations where 'Iniagrape-one' was tested. Spacing $3 \times 3 \mathrm{~m}(1111 \mathrm{vines} / \mathrm{ha}){ }^{\mathrm{z}} 4 \times 1.5 \mathrm{~m}(1667$ vines/ha) ${ }^{\mathrm{y}}$ and $3.5 \times 2.5 \mathrm{~m}(1143$ vines/ha $){ }^{\mathrm{x}}$

${ }^{\mathrm{w}}$ Average cluster and yield per vine count after crop adjustment. Data from $7,{ }^{\mathrm{z}} 9,{ }^{\mathrm{y}}$ and $5^{\mathrm{x}}$ none replicated vines.

${ }^{\mathrm{v}}$ Average berry firmness from 60 berries using FirmTech2 (BioWorks Inc., OK) equipment.

$\mathrm{GA}=$ gibberellic acid; TSS = total soluble solids; TA = titratable acidity.

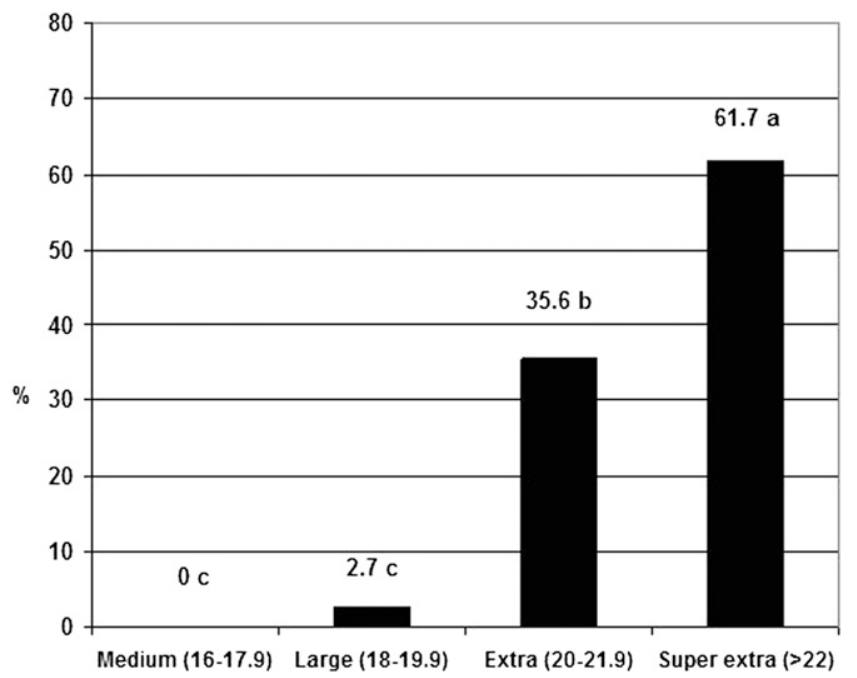

Fig. 2. Average berry size (diameter) distribution of 'Iniagrape-one' applied with gibberellic acid. The data are the means of two sites (Los Andes and Llay-Llay) from the 2010 and 2011 harvest seasons. The means followed by a different letter are significantly different according to the least significant difference honestly significant difference test $(P<0.05)$.

regulator applications, even in warm areas (Fig. 1).

The berries are an attractive shade of blueblack with broad ellipsoid and narrow ellipsoid shapes, a firm berry texture, strong pedicel attachment, and good flavor. The taste
The berries are large, averaging $7.4 \mathrm{~g}$, $21.9 \mathrm{~mm}$ in diameter, and $25.3 \mathrm{~mm}$ long with GA applications. Without hormone treatment, berries averaged $4.3 \mathrm{~g}, 17.6 \mathrm{~mm}$ in diameter, and $18.3 \mathrm{~mm}$ long (Table 2). Figure 2 shows the average berry size distribution in 'Iniagrape-one' treated with GA, where $61.7 \%$ of the bunches showed a berry size higher than $22 \mathrm{~mm}$.

'Iniagrape-one' has firm flesh and tough skin. We have observed that grape berry firmness is considered high when the force $\left(\mathrm{g} \cdot \mathrm{mm}^{-1}\right.$ ) of skin deformation is over $240 \mathrm{~g} \cdot \mathrm{mm}^{-1}$ using a FirmTech 2 device (BioWorks, Wamego, KS). Except for the evaluation of the 2010 season at Los Andes, the berry firmness was above this value (Table 1).

The berries usually contained two to three rudimentary soft seed traces per berry. Occasionally, depending on the location and season, some few berries contain one seed. This behavior is similar to the Autumn Royal cultivar (Dokoozlian et al., 1998).

The new cultivar shows high bud fruitfulness, varying from $73.2 \%$ in the three basal buds of the cane to $93.3 \%$ in buds 8 to 10 . The average cluster number per shoot is 1.5 .

In general, the cluster characteristics in central Chile follow the same trend as in the northern area (Tables 1 and 2).

'Iniagrape-one' reaches commercial maturity in the middle of February in central Chile and one month earlier in northern Chile. 'Iniagrape-one' at Los Andes has been harvested in 9, 16, and 23 Feb., which was 18 to 26 d after 'Flame Seedless' and slightly after 'Midnight Beauty' (6 to $10 \mathrm{~d}$ ) and 'Thompson Seedless' (2 to 7 d) (data not shown). 'Iniagrape-one' has shown a good storage potential that would be considered similar to that reported for 'Midnight Beauty' (Cain, 1998) and better than 'Black Seedless' (data not shown).

\section{Vine}

The Iniagrape-one cultivar is vigorous and produces a strong vine when grafted onto 'Freedom' or 'Harmony' rootstock. Cane or spur-pruning may be used because of the high bud fruitfulness along the shoots. Budbreak occurs in the middle of August and flowering on $\approx 20$ Oct. when cyanamide is sprayed in the winter time ( 8 July) in northern Chile. In the central region where cyanamide is not used, budbreak occurs on or $\approx 22$ Sept. and flowering on or $\approx 15$ Nov.

The internode length at maturity canes varies from 5.5 to $13 \mathrm{~cm}$. The leaf blade is pentagonal-shaped, and the teeth of the leaf margin are convex-shaped on both sides and are green in color. The blade length is $\approx 105$ to $125 \mathrm{~mm}$ long and 175 to $195 \mathrm{~mm}$ wide. The petiole sinuses are slightly open to slightly close; the upper leaf sinuses are open. The leaves are smooth on both sides, and the leaf margin is serrated. On young leaves, the petiole is $\approx 35$ to $50 \mathrm{~mm}$ in length, and its anthocyanin content is of medium intensity. 
Table 2. Berry characteristics of 'Iniagrape-one' table grape applied and non-applied with gibberellic acid $\left(\mathrm{GA}_{3}\right)$ at Vicuña, ${ }^{\mathrm{z}}$ Los Andes, ${ }^{\mathrm{y}}$ and Llay-Llay ${ }^{\mathrm{x}}$ during three years.

\begin{tabular}{|c|c|c|c|}
\hline \multicolumn{4}{|c|}{2009} \\
\hline Characteristic & Vicuña & Los Andes & Llay-Llay \\
\hline \multicolumn{4}{|c|}{ Cluster weight $(\mathrm{g})^{\mathrm{w}}$} \\
\hline Control $^{v}$ & - & $390.5 \pm 35.4 \mathrm{~b}^{\mathrm{u}}$ & $639.4 \pm 24.8 \mathrm{~b}$ \\
\hline $\mathrm{GA}_{3}{ }^{\mathrm{t}}$ & $1114.3 \pm 189.9$ & $698.9 \pm 201.9 \mathrm{a}$ & $1058.8 \pm 100.7 \mathrm{a}$ \\
\hline \multicolumn{4}{|c|}{ Berry weight $(\mathrm{g})^{\mathrm{s}}$} \\
\hline Control $^{v}$ & - & $3.4 \pm 0.2 b$ & $4.4 \pm 0.1 \mathrm{~b}$ \\
\hline $\mathrm{GA}_{3}{ }^{\mathrm{t}}$ & $6.3 \pm 1.0$ & $7.3 \pm 0.6 \mathrm{a}$ & $7.3 \pm 0.9 \mathrm{a}$ \\
\hline \multicolumn{4}{|c|}{ Berry length $(\mathrm{mm})^{\mathrm{s}}$} \\
\hline Control $^{\mathrm{v}}$ & - & $17.6 \pm 0.2 b$ & $18.8 \pm 0.1 \mathrm{~b}$ \\
\hline $\mathrm{GA}_{3}{ }^{\mathrm{t}}$ & - & $25.3 \pm 1.0 \mathrm{a}$ & $22.4 \pm 1.6 \mathrm{a}$ \\
\hline \multicolumn{4}{|c|}{ Berry diameter $(\mathrm{mm})^{\mathrm{s}}$} \\
\hline Controlv $^{v}$ & - & $16.2 \pm 0.2 b$ & $18.3 \pm 0.1 \mathrm{~b}$ \\
\hline $\mathrm{GA}_{3}{ }^{\mathrm{t}}$ & $21.9 \pm 1.2$ & $21.7 \pm 0.6 \mathrm{a}$ & $22.2 \pm 1.3 \mathrm{a}$ \\
\hline \multicolumn{4}{|c|}{2010} \\
\hline Characteristic & Vicuña & Los Andes & Llay-Llay \\
\hline \multicolumn{4}{|c|}{ Cluster weight $(\mathrm{g})^{\mathrm{w}}$} \\
\hline Control $^{\mathrm{v}}$ & - & $322.2 \pm 56.3 \mathrm{~b}$ & $518.2 \pm 65.8 \mathrm{~b}$ \\
\hline $\mathrm{GA}_{3}{ }^{\mathrm{t}}$ & $849.7 \pm 153.4$ & $586.3 \pm 74.6 \mathrm{a}$ & $597.7 \pm 6.1 \mathrm{~b}$ \\
\hline \multicolumn{4}{|c|}{ Berry weight $(\mathrm{g})^{\mathrm{s}}$} \\
\hline Control $^{\mathrm{v}}$ & - & $4.1 \pm 0.1 \mathrm{~b}$ & $4.2 \pm 0.8 \mathrm{~b}$ \\
\hline $\mathrm{GA}_{3}{ }^{\mathrm{t}}$ & $5.8 \pm 0.8$ & $7.7 \pm 0.6 \mathrm{a}$ & $8.3 \pm 0.6 \mathrm{a}$ \\
\hline \multicolumn{4}{|c|}{ Berry length $(\mathrm{mm})^{\mathrm{s}}$} \\
\hline Control $^{v}$ & - & $18.7 \pm 0.5 \mathrm{~b}$ & $16.7 \pm 0.2 \mathrm{~b}$ \\
\hline $\mathrm{GA}_{3}{ }^{\mathrm{t}}$ & - & $25.7 \pm 0.6 \mathrm{a}$ & $24.5 \pm 0.3 \mathrm{a}$ \\
\hline \multicolumn{4}{|c|}{ Berry diameter $(\mathrm{mm})^{\mathrm{s}}$} \\
\hline Control $^{v}$ & - & $18.3 \pm 0.2 b$ & $16.7 \pm 0.3 b$ \\
\hline $\mathrm{GA}_{3}{ }^{\mathrm{t}}$ & $21.5 \pm 0.9$ & $21.6 \pm 0.5 \mathrm{a}$ & $22.4 \pm 0.5 \mathrm{a}$ \\
\hline \multicolumn{4}{|c|}{2011} \\
\hline Characteristic & Vicuña & Los Andes & Llay-Llay \\
\hline \multicolumn{4}{|c|}{$\overline{\text { Cluster weight }(\mathrm{g})^{\mathrm{w}}}$} \\
\hline Control $^{v}$ & - & $557.8 \pm 64.6 \mathrm{~b}$ & $723.3 \pm 30.2 b$ \\
\hline $\mathrm{GA}_{3}{ }^{\mathrm{t}}$ & $869.5 \pm 234.9$ & $826.8 \pm 131.0 \mathrm{a}$ & $841.2 \pm 58.0 \mathrm{a}$ \\
\hline \multicolumn{4}{|c|}{ Berry weight $(\mathrm{g})^{\mathrm{s}}$} \\
\hline Control $^{v}$ & - & $3.9 \pm 0.7 b$ & $5.7 \pm 0.3 \mathrm{~b}$ \\
\hline $\mathrm{GA}_{3}{ }^{\mathrm{t}}$ & $6.4 \pm 0.8$ & $7.9 \pm 0.6 \mathrm{a}$ & $9.7 \pm 0.6 \mathrm{a}$ \\
\hline \multicolumn{4}{|c|}{ Berry length $(\mathrm{mm})^{\mathrm{s}}$} \\
\hline Control $^{\mathrm{v}}$ & - & $17.6 \pm 1.1 \mathrm{~b}$ & $20.2 \pm 0.6 \mathrm{~b}$ \\
\hline $\mathrm{GA}_{3}{ }^{\mathrm{t}}$ & - & $25.2 \pm 1.3 \mathrm{a}$ & $28.8 \pm 1.3 \mathrm{a}$ \\
\hline \multicolumn{4}{|c|}{ Berry diameter $(\mathrm{mm})^{\mathrm{s}}$} \\
\hline Control $^{v}$ & - & $17.2 \pm 0.7 b$ & $19.1 \pm 1.0 \mathrm{~b}$ \\
\hline $\mathrm{GA}_{3}{ }^{\mathrm{t}}$ & $21.5 \pm 1.0$ & $21.5 \pm 0.5 \mathrm{a}$ & $23.0 \pm 1.0 \mathrm{a}$ \\
\hline
\end{tabular}

${ }^{z, y, x}$ Locations where 'Iniagrape-one' was tested. Spacing $3 \times 3 \mathrm{~m}$ (1111 vines $/ \mathrm{ha}^{\mathrm{z}}{ }^{\mathrm{C}} 4 \times 1.5 \mathrm{~m}$ (1667 vines/ ha),$^{\mathrm{y}}$ and $3.5 \times 2.5 \mathrm{~m}\left(1143\right.$ vines/ha). ${ }^{\mathrm{x}}$

${ }^{\mathrm{w}}$ Average cluster weight of 12 -clusters sample.

Data from unreplicated, single vine.

"Means followed by a different letter are significantly different according to analysis of variance honestly significant difference test $(P<0.05)$.

${ }^{\mathrm{t}}$ Data from $7,{ }^{\mathrm{z}} 9,{ }^{\mathrm{y}}$ and $5^{\mathrm{x}}$ none replicated vines. Application of $\mathrm{GA}_{3}, 1 \times 10 \mathrm{mg} \cdot \mathrm{L}^{-1}(2009), 1 \times 15 \mathrm{mg} \cdot \mathrm{L}^{-1}$ (2010), and $2 \times 15 \mathrm{mg} \cdot \mathrm{L}^{-1}(2011)$, spray for thinning plus $2 \times 40 \mathrm{mg} \cdot \mathrm{L}^{-1}$ for berry sizing at Vicuña site; $1 \times 10 \mathrm{mg} \cdot \mathrm{L}^{-1}$ for cluster elongation (rachis, 10 to $12 \mathrm{~cm}$ length), $2 \times 10 \mathrm{mg} \cdot \mathrm{L}^{-1}$ at bloom for thinning, and $3 \times 30 \mathrm{mg} \cdot \mathrm{L}^{-1}$ to increase the berry size at Los Andes and Llay-Llay.

${ }^{\mathrm{s}}$ Average berry weight, length and diameter from $300^{\mathrm{z}}$ and $60^{\mathrm{y}, \mathrm{x}}$ berries \pm SD.

Table 3. Effect of cold storage ( 60 and $90 \mathrm{~d}$ at $\left.0{ }^{\circ} \mathrm{C}\right)$ on the decay, shatter, and berry firmness of 'Iniagrapeone' bunches. ${ }^{2}$

\begin{tabular}{lccc}
\hline & $0 \mathrm{~d}$ & $60 \mathrm{~d}$ & $90 \mathrm{~d}$ \\
\hline Decay (\%) & $0.2 \pm 0.6$ & $0.0 \pm 0.1$ & $3.0 \pm 3.3$ \\
Shattering (\%) & $0.1 \pm 0.3$ & $1.8 \pm 0.7$ & $2.6 \pm 1.7$ \\
Firmness $\left(\mathrm{g} \cdot \mathrm{mm}^{-1}\right)$ & $331.9 \pm 23.5$ & $262.7 \pm 21.9$ & $241.0 \pm 12.1$ \\
\hline
\end{tabular}

${ }^{\mathrm{z}}$ The data are the means of two sites (Los Andes and Llay-Llay) of the 2011 harvest season \pm SD.

\section{Postharvest Performance}

'Iniagrape-one' stores very well up to $90 \mathrm{~d}$ at $0{ }^{\circ} \mathrm{C}$ (Table 3$)$. It has also been observed to have superior shipping quality in other evaluations compared with 'Black Seedless' (data not shown). The berry firmness remains within the commercial standard, and no surface or internal browning was noted throughout the storage period. Moreover, the postharvest berry attachment was good, implying that there are no problems of shattering during harvest or postharvest (less than 5\% shatter). In contrast, 'Midnight Beauty' berry attachment to the pedicel has been classified as medium (Cain, 1998), and the union between the rachis and the pedicel is fragile in 'Autumn Royal' such that the berries can be separated from the rachis during harvesting (Dokoozlian et al., 1998). Unlike 'Autumn Royal', 'Iniagrape-one' has no tendency to crack (Dokoozlian et al., 1998).

After cold storage, the clusters remain in good condition up to $3 \mathrm{~d}$ at room temperature (shelf life).

The edible quality remains high after the cold storage period. Sensory evaluations emphasize the color, appearance, juice content, and flavor of this grape as the main quality characteristics. 'Iniagrape-one' has a distinct, particularly good flavor that is achieved by a balanced sugar:acid ratio both at harvest and after storage.

\section{Recommendations}

This new cultivar could be established in all the present Chilean areas used for table grape production. The potential production for export is high (3000 or more boxes of $8.2 \mathrm{~kg} \cdot \mathrm{ha}^{-1}$ ) considering a number of $\approx 30$ clusters per vine and a density of 1667 vines/ ha (spacing of $3 \times 2 \mathrm{~m}$ ). The distant Asian market appears to be an interesting destination for 'Iniagrape-one' because of its high cold storage capacity. Other target markets such as the United States and the United Kingdom may also be considered.

\section{Availability}

'Iniagrape-one' was registered at "Servicio Agrícola y Ganadero," the Chilean department that controls the process of varietal certification, and a patent application has been submitted to the U.S. Patent and Trademark Office under the name 'Iniagrape-one'.

\section{Literature Cited}

Cain, D. 1998. United States Plant Patent 10,434. Dokoozlian, N., B. Peacock, and D. Luvisi. 1998. Cultural practices for Autumn Royal. The University of California Cooperative Extension, Tulare County, CA.

Emershad, R.L. and D.W. Ramming. 1984. In-ovulo embryo culture of Vitis vinifera L. cv. 'Thompson Seedless'. Amer. J. Bot. 71:873-877.

Emershad, R.L., D.W. Ramming, and M.D. Serpe. 1989. In-ovulo embryo development and plant formation from stenospermic genotypes of Vitis vinifera. Amer. J. Bot. 76:397-402.

Ramming, D.W. 2008. 'Thomcord' Grape. HortScience 43:945-946.

Volosky, S. 1985. Uvas de mesa cultivadas en Chile destinadas a exportación. Variedad Black Seedless. ACONEX. p. 39-43. 